\title{
Biofuel blending reduces particle emissions from aircraft engines at cruise conditions
}

Richard H. Moore ${ }^{1}$, Kenneth L. Thornhill ${ }^{1,2}$, Bernadett Weinzierl ${ }^{3,4}$, Daniel Sauer ${ }^{3,5}$, Eugenio D’Ascoli ${ }^{3,5}$, Jin Kim $^{3}$, Michael Lichtenstern ${ }^{3}$, Monika Scheibe ${ }^{3}$, Brian Beaton ${ }^{1}$, Andreas J. Beyersdorf ${ }^{1,6}$, John Barrick ${ }^{1,2}$, Dan Bulzan ${ }^{7}$, Chelsea A. Corr ${ }^{1,8}$, Ewan Crosbie ${ }^{1,9}$, Tina Jurkat ${ }^{3}$, Robert Martin ${ }^{1}$, Dean Riddick ${ }^{1}$, Michael Shook $^{1,2}$, Gregory Slover $^{1}$, Christiane Voigt ${ }^{3,10}$, Robert White ${ }^{1}$, Edward Winstead ${ }^{1,2}$, Richard Yasky ${ }^{1}$, Luke D. Ziemba ${ }^{1}$, Anthony Brown ${ }^{11}$, Hans Schlager ${ }^{3}$ \& Bruce E. Anderson ${ }^{1}$

\begin{abstract}
Aviation-related aerosol emissions contribute to the formation of contrail cirrus clouds that can alter upper tropospheric radiation and water budgets, and therefore climate ${ }^{1}$. The magnitude of airtraffic-related aerosol-cloud interactions and the ways in which these interactions might change in the future remain uncertain ${ }^{1}$. Modelling studies of the present and future effects of aviation on climate require detailed information about the number of aerosol particles emitted per kilogram of fuel burned and the microphysical properties of those aerosols that are relevant for cloud formation ${ }^{2}$. However, previous observational data at cruise altitudes are sparse for engines burning conventional fuels ${ }^{2,3}$, and no data have previously been reported for biofuel use in-flight. Here we report observations from research aircraft that sampled the exhaust of engines onboard a NASA DC-8 aircraft as they burned conventional Jet $A$ fuel and a 50:50 (by volume) blend of Jet A fuel and a biofuel derived from Camelina oil. We show that, compared to using conventional fuels, biofuel blending reduces particle number and mass emissions immediately behind the aircraft by 50 to 70 per cent. Our observations quantify the impact of biofuel blending on aerosol emissions at cruise conditions and provide key microphysical parameters, which will be useful to assess the potential of biofuel use in aviation as a viable strategy to mitigate climate change.
\end{abstract}

The global aviation sector contributes approximately $5 \%$ of the current anthropogenic radiative forcing, owing to direct emissions of fossil-fuel $\mathrm{CO}_{2}\left(28 \mathrm{~mW} \mathrm{~m}^{-2}\right)$ and the formation and evolution of contrails and contrail-induced cirrus clouds $\left(50 \mathrm{~mW} \mathrm{~m}^{-2}\right)^{1,3-5}$. Of these effects, the largest uncertainties are associated with aviation-induced cloudiness, both directly from contrail-induced cirrus clouds and indirectly from the contribution of black carbon, organic and sulfate aerosols that may act as cloud condensation nuclei and ice nuclei $i^{1,6-8}$. With emissions of $\mathrm{CO}_{2}$ from fuel expected to more than double by 2050, aviation-related contributions to radiative forcing may increase to 3-4 times the year 2000 levels $^{5}$. Consequently, some governments are exploring ways to curb these emissions, and the International Air Transport Association (IATA) has targeted carbon-neutral growth by 2020 and a 50\% reduction in carbon emissions by 2050 (ref. 9).

Sustainable biojet fuels are a promising route for mitigating greenhouse gas emissions. However, many challenges remain before aviation biofuels can be widely adopted, particularly with regard to cost and sustainability. Jet fuels are more highly refined than the biofuels used for surface transportation, with the latter perhaps presenting a "better biomass opportunity cost"10. However, unlike for aviation, there are many alternative energy solutions for surface transportation, other than liquid hydrocarbon-based fuels, that are realizable in the near future ${ }^{10,11}$. Biojet fuels consist of a mixture of $\mathrm{C}_{9}-\mathrm{C}_{16}$ hydrocarbons that are typically formed via transesterification and subsequent hydroprocessing of plant and animal oils to produce a hydrotreated esters and fatty acids (HEFA) fuel that has many of the properties of petroleumderived jet fuels ${ }^{12,13}$. Promising plant-based feed stocks for future aviation biofuels include Jatropha, Camelina and algae $e^{12}$.

Biojet fuels have potential as a future aviation fuel source that is not dependent on fossilized carbon and that contains near-zero levels of sulfur and aromatic species, which are commonly present in petroleumbased jet fuels at levels of several hundred parts per million by mass (p.p.m.m.) sulfur and around $20 \%$ aromatics by volume. Previous laboratory and ground test experiments using bio-based fuels or synthetic Fischer-Tropsch fuels produced from natural gas and coal feed stocks show that the absence of sulfur and aromatic species within the fuel substantially reduces the sulfate and black carbon particle emissions from aircraft engines ${ }^{14-16}$. These results are important for reducing the impact of aviation on local air quality near airports and suggest that similar reductions are likely to be observed at high-altitude cruise conditions; however, the engine operating conditions on the ground (for example, temperature, pressure, fuel flow rates, fuel/air ratio and maximum thrust) are very different from those in flight.

Here we report airborne measurements of jet engine exhaust, sampled at cruise conditions, from engines burning both a blended biofuel and a conventional jet fuel. Research aircraft from NASA, the German Aerospace Center (DLR) and the National Research Council (NRC) Canada were equipped with state-of-the-art instrumentation and sampled the exhaust of the NASA DC- 8 turbofan engines at atmospheric and engine conditions that are exclusively met in flight. The tests were conducted during 2013-2014 as part of the Alternative Fuel Effects on Contrails and Cruise Emissions Study (ACCESS) at NASA Armstrong Flight Research Center in Palmdale, California, USA.

The DC- 8 source aircraft has four wing-mounted CFM56-2-C1 engines that can be fed fuel from any of four segregated fuel tanks within the wings. During the flight experiments, these tanks contained either a medium- or low-sulfur-content Jet A fuel, while a fuselage-mounted auxiliary tank contained an approximately 50:50 (by volume) blend of a low-sulfur-content Jet A fuel and a Camelina-based HEFA biojet fuel (see Methods).

The exhaust plumes from the left and right inboard DC-8 engines were sampled by research aircraft flying in a trailing formation at a distance of $30-150 \mathrm{~m}$ (plume age of about $0.15-0.75 \mathrm{~s}$ ) behind the DC-8 (Fig. 1). This short distance assures that the plumes from specific engines did not mix. Three different fuels and three different engine thrust conditions were investigated, which bracket the range of realistic flight conditions on the DC-8 flight curve (Fig. 1d). Commercial aircraft typically fly at thrust conditions at or slightly above the 'maximum range' point, at which the quotient of drag and Mach 


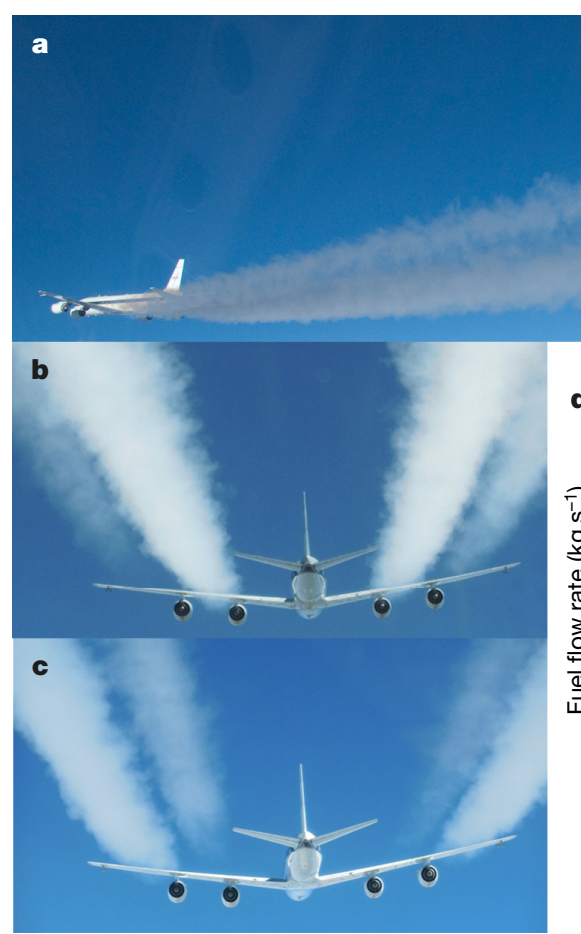

Figure 1 | Side and forward views of DC-8 contrails and the operational cruise curve. a, Side view of the NASA HU-25 Falcon aircraft sampling the DC-8 contrail. b, c, Forward-looking views of the DC- 8 contrails with the inboard engines throttled up to the high-thrust condition and the outboard engines throttled back to almost idle (b), and the reverse conditions (c). d, The operational flight curve for the DC-8 (red curve), assuming an average aircraft gross weight of $90,718 \mathrm{~kg}$ $(200,000 \mathrm{lb})$ at $10,670 \mathrm{~m}$ (flight level, FL310); the red points highlight

number is minimized. Thrust can also be varied by the flight crew for schedule and fuel-burn considerations.

The use of the four-engine DC- 8 is advantageous for in-flight engine emissions testing and overcomes sampling challenges associated with dual-engine flight tests for two reasons. First, the thrust settings of the two inboard engines (no. 2 and no. 3) can be varied over the range of typical flight operating conditions while adjusting the outboard engines (no. 1 and no. 4) to maintain a constant airspeed. Figure $1 \mathrm{~d}$ shows the thrust settings for the DC-8 engines (blue points), which were set at an achievable cruise Mach number of 0.6 for the NASA and DLR chase planes. Second, we can sequentially probe emissions from both inboard engines burning both fuels during a single flight and under the same atmospheric conditions. This allows us to account for differences in engine performance that influence the engine-specific emissions indices. For example, the left inboard engine of the DC-8 emits 1.3-2 times more particles than does the right inboard engine, depending on the thrust setting.

The effect of thrust changes on the emissions of particles and, particularly, water vapour from the engines is visibly evident under contrail-forming conditions, under which the plume is supersaturated with respect to liquid water, satisfying the Schmidt-Appleman criterion ${ }^{17}$. A noticeable decrease in the concentration of ultrafine (less than $10 \mathrm{~nm}$ in diameter) particles was measured under contrailforming conditions versus visually clear air conditions. This difference implies that ice particles collide with and uptake these small particles, thereby decreasing particle number. Consequently, we confine our analysis to the determination of engine emissions indices for clear-air (that is, non-contrail-forming) exhaust plumes only. This ensures that the reported emissions data are not affected by contrail processing in between the engine exhaust plane and the sampling inlet.

Particle number and mass concentrations, as well as trace-gas concentrations of carbon dioxide $\left(\mathrm{CO}_{2}\right)$, carbon monoxide $(\mathrm{CO})$ and

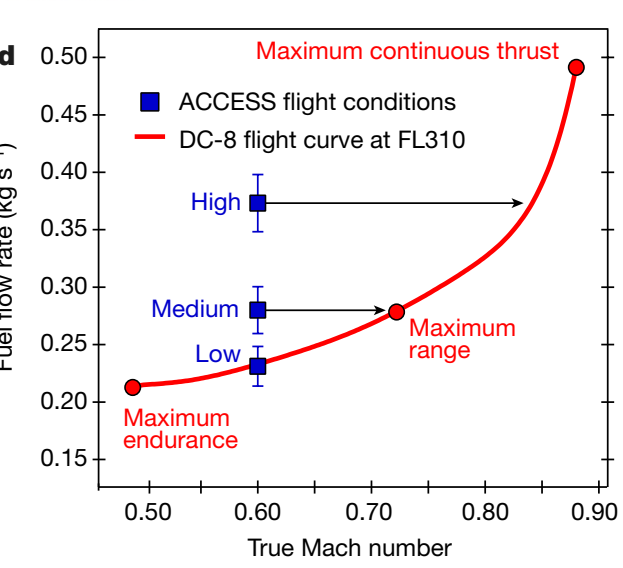

the maximum continuous thrust, range and endurance points. The blue points correspond to the ACCESS engine thrust settings, with the arrows included to guide the eye to the corresponding thrust condition on the flight curve; the blue points denote the mean fuel flow rate \pm 1 arithmetic standard deviation (a.s.d.) during plume sampling of all fuels at altitudes of $9,140-10,970 \mathrm{~m}(30,000-36,000 \mathrm{ft})$. The numbers correspond to the values given in Extended Data Table 2. Note that all emissions indices reported here are for clear air (that is, under non-contrail-forming conditions).

nitrogen oxides $\left(\mathrm{NO}_{x}\right)$, were sampled by the chase aircraft using sample inlets mounted on the crown of the DLR and NASA Falcon aircraft and below-wing-mounted instruments on the NRC T-33. The amount of a given species (number of particles or integrated mass) emitted per kilogram of fuel burned is the species emissions index, which is computed assuming that the carbon content of the fuel is constant and completely converted to $\mathrm{CO}_{2}$ on a mass basis (see Methods). This assumption implies a $\mathrm{CO}_{2}$ emissions index of $3,160 \mathrm{~g} \mathrm{~kg}^{-1}$ (note that here ' $\mathrm{gg}^{-1}$ ' denotes 'per kilogram of fuel').

Table 1 shows the geometric mean (multiplied or divided by one geometric standard deviation (*1 g.s.d.)) particle and trace-gas emissions indices for multiple plume intercepts of the no. 3 engine exhaust plume while it was operating at medium cruise thrust (corresponding to 'maximum range' in Fig. 1d). Summary statistics for the additional thrust conditions and the no. 2 engine are provided in Extended Data Tables 3-7. Particle number emissions indices for the conventional petroleum-based jet fuels are of the order of $10^{14}-10^{15} \mathrm{~kg}^{-1}$, with the non-volatile number emissions index closer to $10^{14} \mathrm{~kg}^{-1}$ and the black-carbon-equivalent mass emissions index near $15 \mathrm{mg} \mathrm{kg}^{-1}$. These emissions indices, and particularly those for the non-volatile particles, fall towards the lower end of reported emissions indices from previous flight test experiments conducted during the 1990s, which is attributable to efficiency gains implemented in the high-bypass CFM56 series of turbofan engines relative to the lower-bypass ATTAS Rolls/Royce/ Snecma M45H Mk501 engines, the P\&W JT3D and JT9D engines, and the GE CF6 series engines ${ }^{18-22}$. Sulfur doping of the low-sulfur-content Jet A from $22 \pm 13$ p.p.m.m. to $416 \pm 37$ p.p.m.m. had no discernible effect on the engine particle emissions for particle diameters exceeding $5-10 \mathrm{~nm}$ (the lowest detectable sizes in this study); however, it is known that changes in the sulfur content of fuel affect the near-field aerosol number emissions index by markedly increasing the number of particles with diameters of less than $5 \mathrm{~nm}$ (ref. 23). In addition, most 
Table 1 | Emission indices for no. 3 engine under medium thrust at cruise conditions

\begin{tabular}{|c|c|c|c|c|c|}
\hline \multirow[b]{2}{*}{ Emissions index (per kg of fuel) } & \multirow{2}{*}{$\begin{array}{c}\begin{array}{c}\text { Medium-sulfur-content } \\
\text { Jet A fuel }\end{array} \\
\text { Emissions index }\end{array}$} & \multicolumn{2}{|c|}{$\begin{array}{l}\text { Low-sulfur-content } \\
\text { Jet A fuel }\end{array}$} & \multicolumn{2}{|c|}{$\begin{array}{l}\text { 50:50 HEFA:low-sulfur-content } \\
\text { Jet A fuel blend }\end{array}$} \\
\hline & & Emissions index & Ratio & Emissions index & Ratio \\
\hline Total particle $\left(D_{\mathrm{p}}>5 \mathrm{~nm}\right)$ number & - & $1.94 \times 10^{15} * 1.53$ & - & $1.58 \times 10^{15} * 1.64$ & - \\
\hline Ultrafine particle $\left(5 \mathrm{~nm}<D_{\mathrm{p}}<10 \mathrm{~nm}\right)$ number & - & $1.40 \times 10^{15} * 1.62$ & - & $1.24 \times 10^{15} * 1.74$ & - \\
\hline Fine particle $\left(D_{\mathrm{p}}>10 \mathrm{~nm}\right)$ number & $6.51 \times 10^{14} * 1.14$ & $7.01 \times 10^{14} * 1.55$ & 1.08 & $3.36 \times 10^{14} * 1.33$ & $0.52^{* * * *}$ \\
\hline Volatile fine particle number & $3.86 \times 10^{14} * 1.08$ & $3.52 \times 10^{14} * 1.74$ & 0.91 & $1.86 \times 10^{14} * 1.38$ & $0.48^{* * * *}$ \\
\hline Non-volatile fine particle number & $2.63 \times 10^{14} * 1.26$ & $3.43 \times 10^{14} * 1.39$ & 1.30 & $1.46 \times 10^{14} * 1.37$ & $0.55^{* *}$ \\
\hline Total particle $\left(5 \mathrm{~nm}<D_{\mathrm{p}}<120 \mathrm{~nm}\right)$ volume $\left(\mathrm{mm}^{3}\right)$ & $16.58 * 1.14$ & $18.03 * 1.85$ & 1.09 & $8.62 * 1.72$ & 0.52 \\
\hline Volatile particle volume $\left(\mathrm{mm}^{3}\right)$ & $5.62 * 1.67$ & $5.98 * 1.86$ & 1.06 & $2.90 * 1.88$ & 0.52 \\
\hline Non-volatile particle volume $\left(\mathrm{mm}^{3}\right)$ & $10.65 * 1.11$ & $12.03 * 1.85$ & 1.13 & $5.42 * 1.73$ & $0.51 * *$ \\
\hline PSAP black-carbon-equivalent mass at $467 \mathrm{~nm}(\mathrm{mg})$ & $17.12 * 1.12$ & $14.48 * 1.24$ & 0.85 & $7.24 * 1.33$ & $0.42 * * * *$ \\
\hline PSAP black-carbon-equivalent mass at $530 \mathrm{~nm}(\mathrm{mg})$ & $16.85 * 1.12$ & $12.89 * 1.36$ & 0.76 & $6.79 * 1.33$ & $0.40 * * * *$ \\
\hline PSAP black-carbon-equivalent mass at $660 \mathrm{~nm}(\mathrm{mg})$ & $16.15 * 1.13$ & $16.07 * 1.16$ & 0.99 & $6.01 * 1.39$ & $0.37^{* * * *}$ \\
\hline Carbon monoxide, $\mathrm{CO}(\mathrm{g})$ & $5.99 \pm 0.96$ & $4.02 \pm 0.54$ & $0.67 * *$ & $4.68 \pm 1.27$ & $0.78^{*}$ \\
\hline Nitrogen oxides, $\mathrm{NO}_{x}(\mathrm{~g})$ & $7.26 \pm 0.50$ & $7.60 \pm 0.41$ & 1.05 & $7.28 \pm 0.33$ & 1.00 \\
\hline Number of plume intercepts & 4 & 5 & & 10 & \\
\hline
\end{tabular}

of the sulfur mass in fuel is emitted as gaseous $\mathrm{SO}_{2}$, which is photooxidized in the atmosphere to form small, secondary sulfate aerosols over longer timescales. Consequently, although our reported total and volatile emissions indices represent the near-field plume, they are a lower limit on the contribution of aircraft emissions to the atmospheric sulfur budget that is ultimately a small global source of pollution relative to terrestrial sources ${ }^{5}$.

We also tabulate emissions indices for the 50:50 blend of HEFA biojet fuel and low-sulfur-content Jet A (Table 1, Extended Data Tables 3-7). The emissions indices from burning the biofuel blend show that both volatile and non-volatile number emissions are reduced by roughly half compared to the Jet A fuels. Ratios of the emissions indices from the low-sulfur-content Jet $\mathrm{A}$ and biofuel blend fuels are given relative to the emissions indices from the medium-sulfur-content fuel, with those in bold denoting a statistically significant difference of means $(P<0.1)$. These large reductions are consistent across each of the investigated engine thrust conditions (Fig. 2), although the number emissions index reduction is less pronounced at the high-engine-thrust setting (about 25\%) than at the low- and medium-thrust settings (about $50 \%)$. Ground-based tests on the DC- 8 engines show a similar trend, albeit over a broader range of fuel flow rates and at sea level ${ }^{16}$. The differences in engine performance characteristics between surface tests and in-flight tests preclude a direct comparison of emissions indices, despite some promising approximation methods that use groundbased data to estimate emissions indices at cruise conditions ${ }^{24-26}$. The greatest effect on emissions is associated with a reduction in black-carbon-equivalent mass, with the biofuel blend exhibiting emissions that are $30 \%-50 \%$ of those seen for the petroleum-based Jet A fuels.

Measured particle size distributions help to explain the differences between the reductions in number and mass (volume) emissions indices for the two fuels (Fig. 3). A pronounced decrease in both total and non-volatile particle number and volume associated with the biofuel blend is apparent, as is a slight shift towards smaller sizes in the mode peak diameter, by $3-5 \mathrm{~nm}$ for the number distributions and $9-12 \mathrm{~nm}$ for the volume distributions. This shift appears to be caused by a greater reduction in the number of larger, soot-mode aerosols, which serve as condensation nuclei for organic species and sulfuric acid. Because gas-to-particle condensation scales with particle size (more specifically, with diameter squared in the free molecular regime), the lower emission of the soot size mode from the biojet fuel blend diminishes the condensational sink, which in turn enhances the nucleation of new particles in a compensating manner.

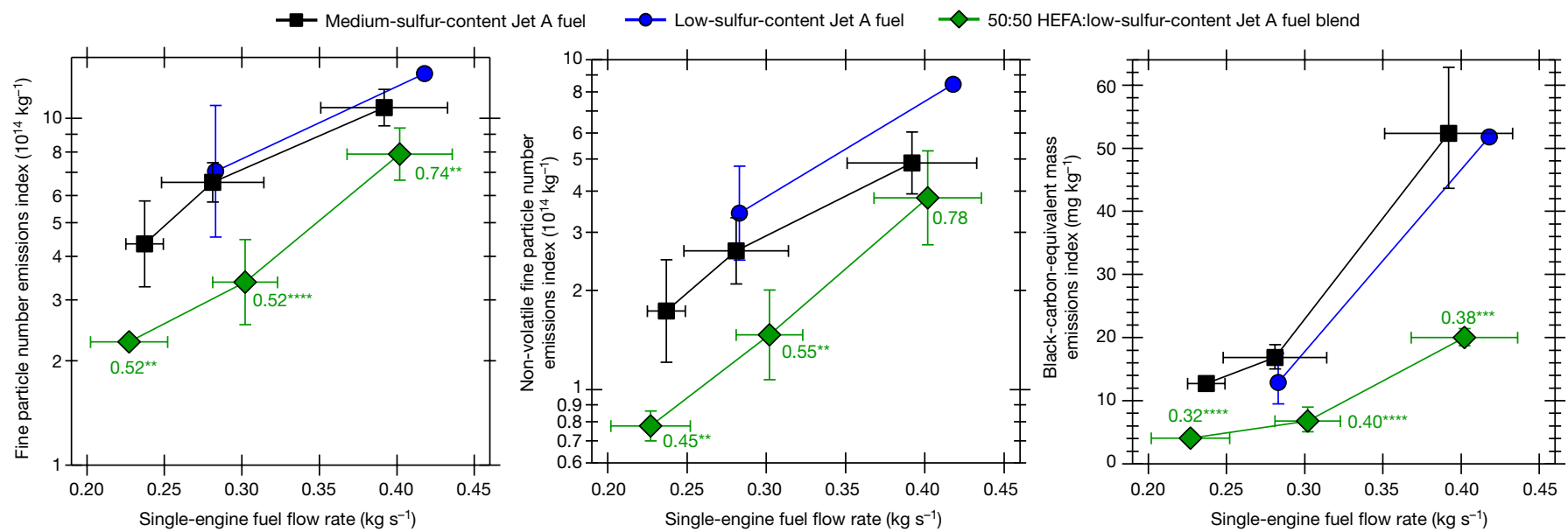

Figure 2 Summary of particle emissions indices at all thrust and cruise conditions. Geometric mean particle emissions indices (*1 g.s.d.) for all thrust settings (shown as fuel flow rate \pm 1 a.s.d.) and each fuel burned on the right inboard engine (no. 3) at altitudes of 9,140-10,970 m $(30,000-36,000 \mathrm{ft})$. The ratio of the emissions indices for the 50:50 biofuel blend and the medium-sulfur-content Jet A fuel are labelled, with the number of asterisks denoting the statistical significance level of a difference in means test: $* * * * P<0.001, * * * P<0.01, * * P<0.05$ (see Table 1 and Extended Data Tables 3-7). 

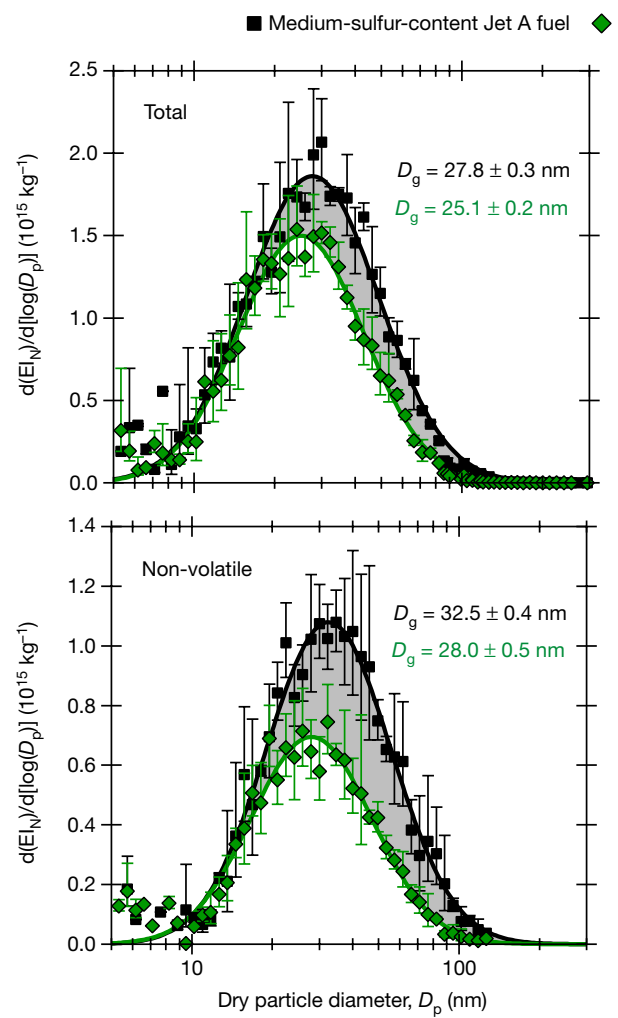

Figure 3 | Size distributions of particle emissions at high-thrust and cruise conditions. Geometric mean ( $* 1$ g.s.d.) size distributions of particle number emissions index $\left(\mathrm{EI}_{\mathrm{N}}\right.$; left $)$ and volume emissions index (EI $;$; right) for the total (top) and non-volatile particle fraction (bottom) measured at the high-thrust condition, behind the no. 3 engine. Black

This competition manifests as the size-dependent number emissions reductions observed in Fig. 3.

We find that blending petroleum-based fuels with a HEFA biojet fuel reduces the volatile and non-volatile particle emissions by $50 \%-70 \%$ at atmospheric cruise conditions. However, the emissions indices for soot particle numbers remain in the soot-rich regime (around $10^{14} \mathrm{~kg}^{-1}$ ) for the biofuel blend. Theoretical calculations ${ }^{3}$ suggest that the initial number of contrail ice particles scales linearly with soot number emissions index in the soot-rich regime and that ambient and ultrafine particles are unlikely to contribute to contrail formation.

Understanding the implications of these findings for future aviation-related effects on upper tropospheric clouds is complicated by the idea that, despite these potential reductions in the number of ice crystals, the frequency and ice mass of contrails may actually increase, owing to the $8 \%$ increase in the hydrogen content of the biofuel blend compared to petroleum-based fuel (Extended Data Table 1). However, it remains to be seen whether this increased water vapour in the early plume is relevant to contrail evolution after the vortex mixing phase, where the supersaturation of ambient water vapour with respect to ice is the primary driver of the persistence and ice mass of contrails ${ }^{27}$. Future modelling studies should explore the extent to which the ice mass concentration of contrails (and hence longwave forcing) might increase, as well as the changes in the optical depth, lifetime and coverage of clouds and the overall radiative forcing associated with reduced ice number concentrations ${ }^{28-30}$. A critical first step is the determination of the number and size of engine exhaust particles at cruise conditions, for which data have so far been non-existent for engines burning biojet fuel blends ${ }^{3}$ and sparse for conventional, petroleum-based fuels ${ }^{2}$. This work provides key microphysical parameters relating to aerosols, which are necessary for transportation and climate modelling efforts to constrain future aviation-related impacts on the environment as the aviation
50:50 HEFA:low-sulfur-content Jet A fuel blend
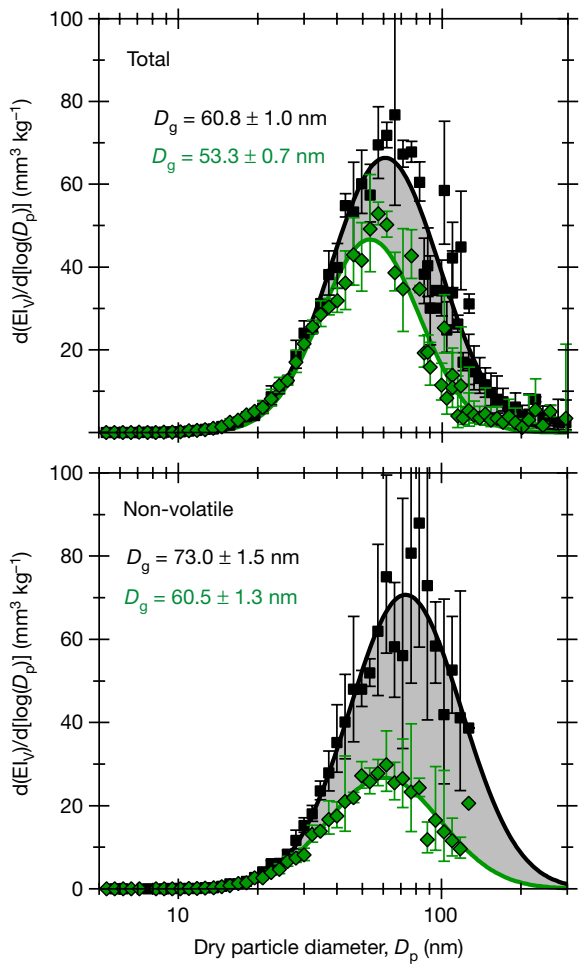

squares and green diamonds show data for the medium-sulfur-content Jet A fuel and the 50:50 biofuel blend, respectively. Solid lines are log-normal fits and the shaded area represents the difference between the two curves. The geometric mean diameter $D_{\mathrm{g}}$ for each fit is noted in the legend; all fit parameters are given in Extended Data Tables 8 and 9.

industry considers transitioning towards more widespread adoption of biofuels.

Online Content Methods, along with any additional Extended Data display items and Source Data, are available in the online version of the paper; references unique to these sections appear only in the online paper.

Received 25 August 2016; accepted 23 January 2017.

1. Boucher, O. et al. in Climate Change 2013: The Physical Science Basis. Contribution of Working Group I to the Fifth Assessment Report of the Intergovernmental Panel on Climate Change (eds Stocker, T. F. et al.) Ch. 7 (Cambridge Univ. Press, 2013).

2. Kärcher, B., Burkhardt, U., Bier, A., Bock, L. \& Ford, I. J. The microphysical pathway to contrail formation. J. Geophys. Res. Atmospheres 120, 7893-7927 (2015).

3. Kärcher, B. The importance of contrail ice formation for mitigating the climate impact of aviation. J. Geophys. Res. Atmospheres 121, 3497-3505 (2016).

4. Burkhardt, U. \& Kärcher, B. Global radiative forcing from contrail cirrus. Nat. Clim. Chang. 1, 54-58 (2011).

5. Lee, D. S. et al. Transport impacts on atmosphere and climate: aviation. Atmos. Environ. 44, 4678-4734 (2010)

6. Brasseur, G. P. et al. Impact of Aviation on Climate: FAA's Aviation Climate Change Research Initiative (ACCRI) Phase II. Bull. Am. Meteorol. Soc. 97, 561-583 (2016).

7. Gettelman, A. \& Chen, C. The climate impact of aviation aerosols. Geophys. Res. Lett. 40, 2785-2789 (2013).

8. Tesche, M., Achtert, P., Glantz, P. \& Noone, K. J. Aviation effects on alreadyexisting cirrus clouds. Nat. Commun. 7, 12016 (2016)

9. Ringbeck, J. V. K. Aviation biofuels: a roadmap towards more carbon-neutral skies. Biofuels 1, 519-521 (2010).

10. Rye, L., Blakey, S. \& Wilson, C. Sustainability of supply or the planet: a review of potential drop-in alternative aviation fuels. Energy Environ. Sci. 3, 17-27 (2010).

11. Warshay, B., Pan, J. \& Sgouridis, S. Aviation industry's quest for a sustainable fuel: considerations of scale and modal opportunity carbon benefit. Biofuels 2 , 33-58 (2011).

12. Law, C. K. Fuel options for next-generation chemical propulsion. AIAA J. 50, 19-36 (2012). 
13. Savage, N. Fuel options: the ideal biofuel. Nature 474, S9-S11 (2011).

14. Corporan, E. et al. Emissions characteristics of a turbine engine and research combustor burning a Fischer-Tropsch jet fuel. Energy Fuels 21, 2615-2626 (2007).

15. Lobo, P., Hagen, D. E. \& Whitefield, P. D. Comparison of PM emissions from a commercial jet engine burning conventional, biomass, and Fischer-Tropsch fuels. Environ. Sci. Technol. 45, 10744-10749 (2011).

16. Moore, R. H. et al. Influence of jet fuel composition on aircraft engine emissions: a synthesis of aerosol emissions data from the NASA APEX, AAFEX, and ACCESS missions. Energy Fuels 29, 2591-2600 (2015).

17. Schumann, U. et al. In situ observations of particles in jet aircraft exhaust and contrails for different sulfur-containing fuels. J. Geophys. Res. Atmospheres 101, 6853-6869 (1996)

18. Anderson, B. E. et al. Airborne observations of aircraft aerosol emissions I: total nonvolatile particle emission indices. Geophys. Res. Lett. 25, 1689-1692 (1998).

19. Schröder, F. P. et al. Ultrafine aerosol particles in aircraft plumes: in situ observations. Geophys. Res. Lett. 25, 2789-2792 (1998).

20. Toon, O. B. \& Miake-Lye, R. C. Subsonic aircraft: contrail and cloud effects special study (SUCCESS). Geophys. Res. Lett. 25, 1109-1112 (1998).

21. Petzold, A., Döpelheuer, A., Brock, C. \& Schröder, F. In situ observations and model calculations of black carbon emission by aircraft at cruise altitude. J. Geophys. Res. Atmospheres 104, 22171-22181 (1999).

22. Schumann, U. et al. Influence of fuel sulfur on the composition of aircraft exhaust plumes: the experiments SULFUR 1-7. J. Geophys. Res. Atmospheres 107, ACC 2-1-ACC 2-27 (2002)

23. Brock, C. A. et al. Ultrafine particle size distributions measured in aircraft exhaust plumes. J. Geophys. Res. Atmospheres 105, 26555-26567 (2000).

24. Petzold, A. \& Döpelheuer, A. Observations of black carbon mass emission indices of a jet engine. Aerosol Sci. Technol. 29, 355-356 (1998).

25. Peck, J., Oluwole, O. O., Wong, H.-W. \& Miake-Lye, R. C. An algorithm to estimate aircraft cruise black carbon emissions for use in developing a cruise emissions inventory. J. Air Waste Manag. Assoc. 63, 367-375 (2013).

26. Stettler, M. E. J., Boies, A. M., Petzold, A. \& Barrett, S. R. H. Global civil aviation black carbon emissions. Environ. Sci. Technol. 47, 10397-10404 (2013).
27. Unterstrasser, S. Properties of young contrails - a parametrisation based on large-eddy simulations. Atmos. Chem. Phys. 16, 2059-2082 (2016).

28. Schumann, U., Jeßberger, P. \& Voigt, C. Contrail ice particles in aircraft wakes and their climatic importance. Geophys. Res. Lett. 40, 2867-2872 (2013)

29. Jeßberger, P. et al. Aircraft type influence on contrail properties. Atmos. Chem. Phys. 13, 11965-11984 (2013).

30. Lewellen, D. C. Persistent contrails and contrail cirrus. Part II: full lifetime behavior. J. Atmos. Sci. 71, 4420-4438 (2014).

Acknowledgements We thank the flight crew of the NASA DC-8 and DLR Falcon, W. Ringelberg, D. Fedors, T. Asher, M. Berry, B. Elit, T. Sandon, P. Weber, R. Welser S. Kaufmann, T. Klausner, A. Reiter, A. Roiger, R. Schlage and U. Schumann for providing meteorological forecasts, and B. Kärcher and P. Le Clercq for discussions. This work was supported by the NASA Advanced Air Vehicles Program, Advanced Air Transport Technology Project, the DLR Aeronautics Research Programme, the Transport Canada Clean Transportation Initiative, and the National Research Council Canada CAAFER Project (46FA-JA12). R.H.M. was supported, in part, by a NASA Postdoctoral Program fellowship. B.W. was supported by the Helmholtz Association (grant number VH-NG-606) and by the European Research Council grant agreement number 640458. C.V. and T.J. were supported by the Helmholtz Association (grant number W2/W3-060) and the German Science Foundation (DFG grant number JU3059/1-1).

Author Contributions R.H.M., B.B., G.S., R.Y., A.B., H.S. and B.E.A. designed and carried out the flight experiment; B.B., J.B., R.M., D.R. and R.W. designed and assisted with the payload integration; R.H.M., K.L.T., B.W., D.S., E.D., J.K., M.L., M.S., D.B., T.J., C.V., E.W., L.D.Z., A.B. and B.E.A. made in-flight measurements and analysed the data; R.H.M. wrote the paper. All authors discussed the results and commented on the manuscript.

Author Information Reprints and permissions information is available at www.nature.com/reprints. The authors declare no competing financial interests. Readers are welcome to comment on the online version of the paper. Correspondence and requests for materials should be addressed to R.H.M. (richard.h.moore@nasa.gov). 


\section{METHODS}

Source aircraft and engines. The NASA DC-8 (Tail Number N817NA) and its four CFM56-2-C1 engines have previously been described in detail ${ }^{16,31-34}$. The engines were installed on the airframe in 1986 and are maintained in accordance with the CFM56-2C and Douglas DC-8 maintenance manuals and inspection task cards. With a maximum take-off thrust of $97,860 \mathrm{~N}$ and an in-flight maximum cruise thrust of $22,150 \mathrm{~N}$, the CFM56-2-C1 is the first high-bypass ( 6.0 bypass ratio) engine of the CFM56 family ${ }^{16,32,35}$. At cruise, the maximum pressure ratio is 31.3 and the cruise bucket-specific fuel consumption is $68.4 \mathrm{~g} \mathrm{~N}^{-1} \mathrm{hr}^{-1}$ (refs 16, 32, 35). Given the use of the aircraft as a NASA flying laboratory, the annual flight hours for the aircraft and engines are typically low $(<1,000 \mathrm{~h})$ as compared to commercial aircraft.

Biofuel blending and ACCESS fuel properties. Blending of conventional jet fuels with biojet fuels is relevant for the aviation fuel supply over the next few decades. For example, the European Advanced Biofuels Flightpath aims to enable around 1.8 million tonnes ( 2 million tons) of sustainable aviation biofuels to be in use by $2020^{36}$. Meanwhile, the US Farm-to-Fly initiative will accelerate biofuel development, and the US Federal Aviation Administration (FAA) targets annual production of 4.5 billion litres ( 1 billion gallons) of drop-in renewable jet fuel by $2018^{37}$. For comparison, the FAA target is roughly $6 \%$ of the US domestic production of jet fuel and $1 \%$ of the global jet fuel consumption expected for $2018^{38,39}$. Here we examine the emissions from three different fuels: a low-sulfur-content Jet A fuel, a medium-sulfur-content Jet A fuel, and a 50:50 (by volume) blend of the lowsulfur-content Jet A fuel and an HEFA biojet fuel. The medium-sulfur-content Jet A fuel was created by doping the low-sulfur-content Jet $A$ fuel that was delivered from the refinery with a small aliquot of tetrahydrothiophene to increase the sulfur content of the fuel to $416 \pm 37$ p.p.m.m. without changing its other properties. Typical sulfur concentrations in petroleum-based jet fuels are of the order of several hundred parts per million by mass.

The main difference between the HEFA fuel and traditional petroleum-based fuels is that the former contains no sulfur or aromatic species, whereas traditional jet fuels typically have aromatic contents of $18 \%-25 \%$. In addition to strict standards related to fuel density, viscosity and freezing behaviour that affect safety of flight, fuel aromatics are limited to below $25 \%$ to limit solvent deterioration of nitrile elastomers; meanwhile, a minimum aromatic content of $8 \%$ was established to swell the elastomer seals in some current fuel systems $s^{40-42}$. For this reason, only 50:50 (by volume) blends of HEFA and petroleum-based fuels are currently certified for flight. All investigated fuels were tested before use and conform to fligh worthiness specifications outlined by ASTM ${ }^{43,44}$; the ACCESS fuel properties are summarized in Extended Data Table 1.

Particle and trace gas measurements. Measurements were made from the NASA HU-25 Falcon aircraft using the NASA Langley Aerosol Research Group (LARGE) suite of in situ instruments, which have been used for numerous airborne research campaigns, as described elsewhere ${ }^{18}$. Similarly, the instruments onboard the DLR Falcon 20 and NRC T-33 aircraft are well characterized with long flight heritage $^{21,45}$. Results from the following instruments were used here. Total particle number concentration $\left(D_{\mathrm{p}}>5 \mathrm{~nm}\right)$ was measured by a custom condensation particle counter (CPC) onboard the DLR Falcon 20. Fine particle number concentration $\left(D_{\mathrm{p}}>10 \mathrm{~nm}\right)$ was measured on the NRC T-33 by a TSI $7610 \mathrm{CPC}$, and on the HU- 25 by a pair of TSI 3010 CPCs; one of the HU-25 CPCs measured the non-volatile particle fraction after sample treatment with a thermal denuder at $350^{\circ} \mathrm{C}$, and the other measured the total (volatile and non-volatile) aerosol number. Similarly, total and non-volatile particle size distributions were measured by a TSI nano Scanning Mobility Particle Sizer (nanoSMPS; 3936, 3085, 3025A) for thermally undenuded and denuded sample streams, respectively. Because the nanoSMPS requires $45 \mathrm{~s}$ to complete a size upscan, a dual lag chamber system was used, where two cylinders were charged at high flow rate $\left(191 \mathrm{~min}^{-1}\right)$ while the aircraft was sampling the exhaust plume. These lag chambers were then sampled by the nanoSMPS at $1.51 \mathrm{~min}^{-1}$. The upper portion of the size distribution $\left(D_{\mathrm{p}}>85 \mathrm{~nm}\right)$ was measured by an ultrahigh-sensitivity aerosol size spectrometer (UHSAS; Droplet Measurement Technologies), which was calibrated using soot particles from a Mini-CAST soot generator that were size-classified with a differential mobility analyser ${ }^{46}$. The nanoSMPS size distributions were integrated to yield the total and non-volatile particle volume. Finally, particle black-carbonequivalent masses at three different optical wavelengths were measured by a Radiance Research Particle Soot Absorption Photometer (PSAP), assuming a mass absorption coefficient (MAC) of $7.5 \mathrm{~m}^{2} \mathrm{~g}^{-1}$ at $550 \mathrm{~nm}$ (ref. 47). This MAC was corrected for each of the PSAP wavelengths assuming an inverse wavelength dependence to yield MACs of $8.83 \mathrm{~m}^{2} \mathrm{~g}^{-1}, 7.78 \mathrm{~m}^{2} \mathrm{~g}^{-1}$ and $6.25 \mathrm{~m}^{2} \mathrm{~g}^{-1}$ at wavelengths of $467 \mathrm{~nm}$, $530 \mathrm{~nm}$ and $660 \mathrm{~nm}$, respectively. The PSAP mass concentrations were corrected for filter scattering artefacts following ref. 48 , assuming a single scattering albedo (SSA) of 0.1 , which is consistent with Mie theory calculations using the measured size distribution and a black-carbon refractive index of $1.95-0.75 i$ (ref. 47 ).
The PSAP correction is weakly sensitive to this assumed SSA and varies by only $1 \%$ over the SSA range of $0.03-0.3$.

Carbon dioxide $\left(\mathrm{CO}_{2}\right)$, carbon monoxide $(\mathrm{CO})$ and nitrogen oxide $\left(\mathrm{NO}_{x}\right)$ concentrations were measured using Los Gatos Research instruments. $\mathrm{CO}$ and $\mathrm{CO}_{2}$ were measured via cavity-enhanced absorption. To measure $\mathrm{NO}_{x}$, the sample stream was mixed with excess ozone to convert $\mathrm{NO}$ to $\mathrm{NO}_{2}$, which was measured via cavity ring-down spectroscopy.

Calculation of emissions indices. As the Falcon sampling probe traverses the DC-8 engine exhaust it encounters varying concentrations of particles and trace gases owing to the spatial inhomogeneity of the plume. Making sense of these time-varying quantities requires that we normalize them to the rate of fuel burned by the engines to arrive at an averaged emissions index across the plume. The emissions index (EI) of particle or trace-gas species $\mathrm{X}$ is determined as

$$
\mathrm{EI}_{\mathrm{X}}=\frac{\Delta \mathrm{X} \times S(\mathrm{X})}{\Delta \mathrm{CO}_{2}}\left(\mathrm{EI}_{\mathrm{CO}_{2}}\right)
$$

where $\Delta \mathrm{X}$ and $\Delta \mathrm{CO}_{2}$ are the dilution-corrected, background-subtracted peak areas of the measured concentrations of species $\mathrm{X}$ and $\mathrm{CO}_{2}$ at standard temperature and pressure (STP), respectively. $S(\mathrm{X})$ is a unit-conversion scaling factor for particle concentrations (number or mass per air volume at STP) or trace-gas concentrations (parts per million by volume), defined as

$$
S(\mathrm{X})= \begin{cases}V_{\mathrm{m}} / M_{\mathrm{CO}_{2}} & \text { for particles } \\ M_{\mathrm{X}} / M_{\mathrm{CO}_{2}} & \text { for trace gases }\end{cases}
$$

where $V_{\mathrm{m}}$ is the molar volume of ideal gas at STP $\left(22.41 \mathrm{~mol}^{-1}\right)$, and $M_{\mathrm{X}}$ and $M_{\mathrm{CO}_{2}}$ are the molar masses of species $\mathrm{X}$ and $\mathrm{CO}_{2}$, respectively. $\mathrm{EI}_{\mathrm{CO}_{2}}$ is the emissions index of $\mathrm{CO}_{2}$, assuming the carbon content in the fuel is constant and is completely converted to $\mathrm{CO}_{2}$, and is defined as

$$
\mathrm{EI}_{\mathrm{CO}_{2}}=\frac{R T}{P V_{\mathrm{m}}} \frac{M_{\mathrm{CO}_{2}}}{\left(M_{\mathrm{C}}+\alpha M_{\mathrm{H}}\right)} \approx 3,160 \mathrm{~g} \mathrm{~kg}^{-1}
$$

where $R$ is the ideal gas constant, $T$ is the temperature at STP $(273.15 \mathrm{~K}), P$ is the pressure at STP (1 atm), $\alpha$ is the hydrogen-to-carbon molar ratio of the fuel, and $M_{\mathrm{C}}$ and $M_{\mathrm{H}}$ are the molar masses of carbon and hydrogen, respectively. Values of $\alpha$ calculated from Extended Data Table 1 for the Jet A fuels and the blended fuel are 1.92 and 2.07, respectively; however, for this analysis, we assume a constant value of 1.92 for simplicity. This assumption introduces insignificant error (about 1\%) into the reported emissions indices compared to the measurement uncertainties.

The emissions indices reported here are tabulated as geometric means $* 1$ g.s.d. for particle emissions indices and as arithmetic means \pm 1 a.s.d. for the trace-gas emissions indices. The statistical significance of the difference in means is assessed using Welch's unequal variances $t$-test.

Particle sampling and transmission loss corrections. The size-dependent inlet aspiration efficiency of the NASA HU-25 HIMIL inlet and particle losses to the sampling lines are estimated using the Particle Loss Calculator ${ }^{49}$, which accounts for diffusional, inertial and sedimentation losses. Particles were sampled at a flow rate of $371 \mathrm{~min}^{-1}$ through a $4.35-\mathrm{mm}$ tube that was assumed to be oriented parallel to the air flow around the aircraft (mean air velocity of about $200 \mathrm{~m} \mathrm{~s}^{-1}$ ). In reality, the inlet tube is shrouded, which ensures parallel sampling streamlines, but which reduces the local air velocity by an unknown amount. However, the sensitivity of the inlet aspiration efficiency to airspeed is negligible for the ultrafine particles sampled during ACCESS. The sample then passes through approximately $0.34 \mathrm{~m}$ of tubing with an inner diameter of $4.35 \mathrm{~mm}$ and approximately $4 \mathrm{~m}$ of tubing with an inner diameter of $7.9 \mathrm{~mm}$ before being sampled by the instrumentation in the cabin of the chase plane. We find that the uncertainty associated with particles larger than $20 \mathrm{~nm}$ in diameter is within $10 \%$, but that large corrections (about $40 \%$ ) are necessary at the lowest particle sizes (diameters of $<10 \mathrm{~nm}$ ). Given uncertainties associated with the CPC detection efficiency curves, we choose not to apply these corrections to the tabulated integrated number, volume and mass emission indices (Table 1 and Extended Data Tables 3-7), following ref. 33. Instead we focus on the differences in the sampled emissions indices across fuel types and engine powers, for which the sampling characteristics and efficiency should be nearly the same. On the basis of the measured mean size distributions, we estimate the uncertainty associated with neglecting these corrections on the tabulated number emissions indices to be $7 \%-9 \%$ and on the volume and mass emissions indices to be around 3\%. The variability in the measured data (as expressed by the g.s.d. about the geometric mean) is typically much larger than $10 \%$. Log-normal size distributions discussed in the next section have been corrected for these sampling and transmission losses. 
Particle size distribution log-normal fits. Particle number and volume size distributions (5-300 $\mathrm{nm}$ diameter) measured by the SMPS and UHSAS were fitted using a single-mode log-normal function of the form

$$
\frac{\mathrm{d}\left(\mathrm{EI}_{i}\right)}{\mathrm{d}\left[\log \left(D_{\mathrm{p}}\right)\right]}=\frac{i}{\sqrt{2 \pi} \log \left(\sigma_{\mathrm{g}, i}\right)} \exp \left\{-\frac{\left[\log \left(D_{\mathrm{p}}\right)-\log \left(D_{\mathrm{g}, i}\right)\right]^{2}}{2\left[\log \left(\sigma_{\mathrm{g}, i}\right)\right]^{2}}\right\}
$$

where $i$ is the total particle number $(N)$ or volume $(V), \mathrm{EI}_{i}$ is the corresponding emissions index, $D_{\mathrm{p}}$ is the dry particle diameter, $D_{\mathrm{g}, i}$ is the geometric mean diameter and $\sigma_{\mathrm{g}, i}$ is the g.s.d. Fit coefficients for the number and volume size distributions are given in Extended Data Tables 8 and 9. All size distributions have been corrected for particle sampling and transmission losses.

Sample size. No statistical methods were used to predetermine sample size.

Data availability. The datasets generated during and/or analysed during this study are available in the NASA Aeronautics Flight Projects repository at http://aero-fp. larc.nasa.gov/ and from the corresponding author on reasonable request.

31. Wey, C. C. et al. Overview on the aircraft particle emissions experiment (APEX). J. Propuls. Power 23, 898-905 (2007)

32. Anderson, B. et al. Alternative Aviation Fuel Experiment (AAFEX). Report No. NASA/TM-2011-217059 (NASA, 2011).

33. Beyersdorf, A. J. et al. Reductions in aircraft particulate emissions due to the use of Fischer-Tropsch fuels. Atmos. Chem. Phys. 14, 11-23 (2014).

34. Onasch, T. B. et al. Chemical properties of aircraft engine particulate exhaust emissions. J. Propuls. Power 25, 1121-1137 (2009).

35. The Technology Behind the CFM56-2 Turbofan Engine https://web.archive.org/ web/20120430172000/http://www.cfm56.com/products/cfm56-2/ cfm56-2-technology (accessed 11 May 2016)

36. European Advanced Biofuels Flight Path Initiative http://ec.europa.eu/energy/ en/topics/biofuels/biofuels-aviation (accessed 22 July 2016).

37. Agriculture and Aviation: Partners in Prosperity http://www.caafi.org/files/ usda-farm-to-fly-report-jan-2012.pdf (US Department of Agriculture, 2012).
38. Aviation Outlook http://www.icao.int/environmental-protection/Documents/ EnvironmentReport-2010/ICAO_EnvReport10-Outlook_en.pdf (International Civil Aviation Organization, 2010).

39. Annual Energy Outlook 2016: Petroleum and Other Liquids Supply and Disposition http://www.eia.gov/forecasts/aeo/data/browser/\#/?id=11AEO2016\&region $=0-0 \&$ cases $=$ ref2016 $\sim$ ref $\_$no $c p p \& s t a r t=2014 \&$ end $=2018$ $\& f=A \&$ linechart=ref2016-d032416a.3-11-AEO2016 ref_no_cppd032316a.3-11-AEO2016\&sourcekey=0 (US Energy Information Administration, 2016).

40. Moses, C. A. \& Roets, P. N. Properties, characteristics, and combustion performance of Sasol fully synthetic jet fuel. J. Eng. Gas Turbines Power 131, 041502 (2009).

41. Corporan, E. et al. Chemical, thermal stability, seal swell, and emissions studies of alternative jet fuels. Energy Fuels 25, 955-966 (2011).

42. DeWitt, M. J., Corporan, E., Graham, J. \& Minus, D. Effects of aromatic type and concentration in Fischer-Tropsch fuel on emissions production and material compatibility. Energy Fuels 22, 2411-2418 (2008).

43. ASTM International. ASTM D1655: Standard Specification for Aviation Turbine Fuels http://www.astm.org/Standards/D1655.htm (2016)

44. ASTM International. ASTM D7566: Standard Specification for Aviation Turbine Fuel Containing Synthesized Hydrocarbons http://www.astm.org/Standards/ D7566.htm (2016).

45. Voigt, C. et al. In-situ observations of young contrails: overview and selected results from the CONCERT campaign. Atmos. Chem. Phys. 10, 9039-9056 (2010).

46. Moore, R. H. et al. Mapping the operation of the Miniature Combustion Aerosol Standard (Mini-CAST) soot generator. Aerosol Sci. Technol. 48, 467-479 (2014).

47. Bond, T. C. \& Bergstrom, R. W. Light absorption by carbonaceous particles: an investigative review. Aerosol Sci. Technol. 40, 27-67 (2006).

48. Virkkula, A. Correction of the calibration of the 3-wavelength Particle Soot Absorption Photometer (3ג PSAP). Aerosol Sci. Technol. 44, 706-712 (2010).

49. von der Weiden, S.-L., Drewnick, F. \& Borrmann, S. Particle Loss Calculatora new software tool for the assessment of the performance of aerosol inlet systems. Atmos. Meas. Tech. 2, 479-494 (2009). 


\section{RESEARCH LETTER}

Extended Data Table 1 | Mean fuel properties ( \pm 1 a.s.d.) for each of the three fuels investigated

\begin{tabular}{lcccc}
\hline Fuel Property & $\begin{array}{c}\text { Medium-sulfur- } \\
\text { content Jet A fuel }\end{array}$ & $\begin{array}{c}\text { Low-sulfur- } \\
\text { content Jet A fuel }\end{array}$ & $\begin{array}{c}\text { 50:50 HEFA:low-sulfur- } \\
\text { content Jet A fuel blend }\end{array}$ & $\begin{array}{c}\text { Jet A Specification } \\
\text { Range }^{\dagger}\end{array}$ \\
\hline Sulfur (p.p.m.m.) & $416 \pm 37$ & $22 \pm 13$ & $11 \pm 3$ & $<3000$ \\
Aromatics (per cent by volume) & $21.1 \pm 0.7$ & $21.4 \pm 1.4$ & $12.9 \pm 1.2$ & $8-25$ \\
Hydrogen Content (per cent by mass) & $13.6 \pm 0.3$ & $13.8 \pm 0.2$ & $14.7 \pm 0.2$ & $>13.4$ \\
Naphthalenes (per cent by volume) & $0.68 \pm 0.04$ & $0.68 \pm 0.05$ & $0.4 \pm 0.0$ & $<3.0$ \\
Density (kg m ${ }^{-3}$ ) & $809.2 \pm 1.8$ & $810 \pm 0.5$ & $787.4 \pm 2.5$ & $775-840$ \\
Net Heat of Combustion (MJ kg ${ }^{-1}$ ) & $43.14 \pm 0.05$ & $43.15 \pm 0.06$ & $43.52 \pm 0.04$ & $>42.8$ \\
\hline Number of Samples Tested & 5 & 4 & 5 & \\
\hline
\end{tabular}

${ }^{\dagger}$ ASTM D1655 (ref. 43) and D7566 (ref. 44). 
Extended Data Table 2 | Summary of cruise emissions index tables

\begin{tabular}{|c|c|c|c|}
\hline & \multicolumn{3}{|c|}{ Engine thrust condition (fuel flow in $\mathrm{kg} \mathrm{s}^{-1}$ ) } \\
\hline & $\begin{array}{c}\text { High } \\
(0.373 \pm 0.025)\end{array}$ & $\begin{array}{c}\text { Medium } \\
(0.280 \pm 0.020)\end{array}$ & $\begin{array}{c}\text { Low } \\
(0.231 \pm 0.017)\end{array}$ \\
\hline Engine \#2 & Extended Data Table 3 & Extended Data Table 5 & Extended Data Table 6 \\
\hline Engine \#3 & Extended Data Table 4 & Table 1 in main text & Extended Data Table 7 \\
\hline
\end{tabular}




\section{RESEARCH LETTER}

Extended Data Table 3 | Emissions indices for no. 2 engine under high-thrust and cruise conditions

\begin{tabular}{|c|c|c|c|c|c|}
\hline \multirow[b]{2}{*}{ Emissions index (per kg of fuel) } & \multirow{2}{*}{$\begin{array}{c}\text { Medium-sulfur-content } \\
\text { Jet A fuel }\end{array}$} & \multicolumn{2}{|c|}{$\begin{array}{l}\text { Low-sulfur-content } \\
\text { Jet A fuel }\end{array}$} & \multicolumn{2}{|c|}{$\begin{array}{c}\text { 50:50 HEFA:low-sulfur-content } \\
\text { Jet A fuel blend }\end{array}$} \\
\hline & & Emissions index & Ratio & Emissions index & Ratio \\
\hline Total particle $\left(D_{p}>5 \mathrm{~nm}\right)$ number & - & $3.30 \times 10^{15} * 1.04$ & - & $1.97 \times 10^{15} * 1.48$ & - \\
\hline Ultrafine particle $\left(5<D_{p}<10 \mathrm{~nm}\right)$ number & - & $1.81 \times 10^{15} * 1.08$ & - & $1.08 \times 10^{15} * 1.99$ & - \\
\hline Fine particle $\left(D_{p}>10 \mathrm{~nm}\right)$ number & $1.43 \times 10^{15} * 1.13$ & $1.57 \times 10^{15}$ & 1.10 & $1.02 \times 10^{15} * 1.16$ & $0.71^{* * *}$ \\
\hline Volatile fine particle number & $7.58 \times 10^{14} * 1.27$ & $6.53 \times 10^{14}$ & 0.86 & $5.06 \times 10^{14} * 1.09$ & $0.67^{*}$ \\
\hline Non-volatile fine particle number & $6.59 \times 10^{14} * 1.08$ & $9.17 \times 10^{14}$ & 1.39 & $5.03 \times 10^{14} * 1.30$ & $0.76^{* *}$ \\
\hline Total particle $\left(5<D_{p}<120 \mathrm{~nm}\right)$ volume $\left(\mathrm{mm}^{3}\right)$ & $68.23 * 1.31$ & 78.80 & 1.16 & $37.77 * 1.15$ & 0.55 \\
\hline Volatile particle volume $\left(\mathrm{mm}^{3}\right)$ & $20.07 * 1.12$ & 29.71 & 1.48 & $15.79 * 1.20$ & 0.79 \\
\hline Non-volatile particle volume $\left(\mathrm{mm}^{3}\right)$ & $46.02 * 1.55$ & 49.09 & 1.07 & $21.65 * 1.21$ & 0.47 \\
\hline PSAP black-carbon-equivalent mass at $467 \mathrm{~nm}(\mathrm{mg})$ & $85.13 * 1.12$ & 70.49 & 0.83 & $38.94 * 1.37$ & $0.46^{\star \star \star \star}$ \\
\hline PSAP black-carbon-equivalent mass at $530 \mathrm{~nm}(\mathrm{mg})$ & $82.40 * 1.12$ & 67.94 & 0.82 & $37.55 * 1.39$ & $0.46^{* * * *}$ \\
\hline PSAP black-carbon-equivalent mass at $660 \mathrm{~nm}(\mathrm{mg})$ & $75.38 * 1.12$ & 66.43 & 0.88 & $36.84 * 1.39$ & $0.49^{* * *}$ \\
\hline Carbon monoxide, $\mathrm{CO}(\mathrm{g})$ & $5.62 \pm 0.95$ & 3.57 & 0.64 & $4.43 \pm 1.17$ & 0.79 \\
\hline Nitrogen oxides, $\mathrm{NO}_{\mathrm{x}}(\mathrm{g})$ & $9.67 \pm 0.71$ & - & - & $9.61 \pm 0.80$ & 0.99 \\
\hline Number of plume intercepts & 4 & 1 & & 7 & \\
\hline
\end{tabular}


Extended Data Table 4 | Emissions indices for no. 3 engine under high-thrust and cruise conditions

\begin{tabular}{|c|c|c|c|c|c|}
\hline \multirow[b]{2}{*}{ Emissions index (per kg of fuel) } & \multirow{2}{*}{$\begin{array}{c}\begin{array}{c}\text { Medium-sulfur-content } \\
\text { Jet A fuel }\end{array} \\
\text { Emissions index }\end{array}$} & \multicolumn{2}{|c|}{$\begin{array}{l}\text { Low-sulfur-content } \\
\text { Jet A fuel }\end{array}$} & \multicolumn{2}{|c|}{$\begin{array}{c}\text { 50:50 HEFA:low-sulfur-content } \\
\text { Jet A fuel blend }\end{array}$} \\
\hline & & Emissions index & Ratio & Emissions index & Ratio \\
\hline Total particle $\left(D_{p}>5 \mathrm{~nm}\right)$ number & - & $2.11 \times 10^{15} * 1.23$ & - & $1.62 \times 10^{15} * 1.44$ & - \\
\hline Ultrafine particle $\left(5<D_{p}<10 \mathrm{~nm}\right)$ number & - & $1.16 \times 10^{15} * 1.45$ & - & $9.15 \times 10^{14} * 1.12$ & - \\
\hline Fine particle $\left(D_{n}>10 \mathrm{~nm}\right)$ number & $1.07 \times 10^{15} * 1.13$ & $1.34 \times 10^{15}$ & 1.25 & $7.87 \times 10^{14} * 1.19$ & $0.74^{\star *}$ \\
\hline Volatile fine particle number & $5.81 \times 10^{14} * 1.07$ & $4.97 \times 10^{14}$ & 0.86 & $3.98 \times 10^{14} * 1.06$ & $0.69^{* * * *}$ \\
\hline Non-volatile fine particle number & $4.86 \times 10^{14} * 1.24$ & $8.43 \times 10^{14}$ & 1.74 & $3.81 \times 10^{14} * 1.39$ & 0.78 \\
\hline Total particle $\left(5<D_{p}<120 \mathrm{~nm}\right)$ volume $\left(\mathrm{mm}^{3}\right)$ & $44.30 * 1.14$ & 50.01 & 1.13 & $23.32 * 1.14$ & $0.53^{*}$ \\
\hline Volatile particle volume $\left(\mathrm{mm}^{3}\right)$ & $9.51 * 1.54$ & 13.53 & 1.42 & $9.39 * 1.54$ & 0.99 \\
\hline Non-volatile particle volume $\left(\mathrm{mm}^{3}\right)$ & $32.81 * 1.34$ & 36.48 & 1.11 & $13.27 * 1.06$ & 0.40 \\
\hline PSAP black-carbon-equivalent mass at $467 \mathrm{~nm}(\mathrm{mg})$ & $54.00 * 1.20$ & 53.55 & 0.99 & $20.84 * 1.07$ & $0.39^{* * *}$ \\
\hline PSAP black-carbon-equivalent mass at $530 \mathrm{~nm}(\mathrm{mg})$ & $52.38 * 1.20$ & 51.77 & 0.99 & $20.00 * 1.07$ & $0.38^{\star * *}$ \\
\hline PSAP black-carbon-equivalent mass at $660 \mathrm{~nm}(\mathrm{mg})$ & $50.95 * 1.20$ & 50.10 & 0.98 & $19.54 * 1.07$ & $0.38^{\star \star *}$ \\
\hline Carbon Monoxide, $\mathrm{CO}(\mathrm{g})$ & $5.18 \pm 0.72$ & 3.82 & 0.74 & $4.70 \pm 1.20$ & 0.91 \\
\hline Nitrogen Oxides, $\mathrm{NO}_{\mathrm{x}}(\mathrm{g})$ & $9.45 \pm 0.49$ & 9.77 & 1.03 & $9.03 \pm 0.58$ & 0.96 \\
\hline Number of Plume Intercepts & 4 & 1 & & 5 & \\
\hline
\end{tabular}

Emissions indices were measured in clear air at a single-engine fuel flow rate of $0.373 \pm 0.025 \mathrm{~kg} \mathrm{~s}^{-1}$. Data are for the right inboard engine (no. 3) at altitudes of 9,140-10,970 $\mathrm{m}(30,000-36,000 \mathrm{ft})$. Significance level: $* * * * P<0.001, * * * P<0.01, * * P<0.05, * P<0.1$. Particle emissions indices are reported as the geometric mean $* 1$ g.s.d.; trace-gas emissions indices are reported as the arithmetic mean \pm 1 a.s.d. 


\section{RESEARCH LETTER}

Extended Data Table 5 | Emissions indices for no. 2 engine under medium-thrust and cruise conditions

\begin{tabular}{|c|c|c|c|c|c|}
\hline \multirow[b]{2}{*}{ Emissions index (per kg of fuel) } & \multirow{2}{*}{$\begin{array}{c}\text { Medium-sulfur-content } \\
\text { Jet A fuel }\end{array}$} & \multicolumn{2}{|c|}{$\begin{array}{l}\text { Low-sulfur-content } \\
\text { Jet A fuel }\end{array}$} & \multicolumn{2}{|c|}{$\begin{array}{c}\text { 50:50 HEFA:low-sulfur-content } \\
\text { Jet A fuel blend }\end{array}$} \\
\hline & & Emissions index & Ratio & Emissions index & Ratio \\
\hline Total particle $\left(D_{p}>5 n m\right)$ number & - & $3.25 \times 10^{15} * 1.09$ & - & $2.77 \times 10^{15} * 1.24$ & - \\
\hline Ultrafine particle $\left(5<D_{p}<10 \mathrm{~nm}\right)$ number & - & $2.26 \times 10^{15} * 1.10$ & - & $2.23 \times 10^{15} * 1.24$ & - \\
\hline Fine particle $\left(D_{p}>10 \mathrm{~nm}\right)$ number & $9.97 \times 10^{14} * 1.14$ & $1.12 \times 10^{15} * 1.28$ & 1.12 & $6.01 \times 10^{14} * 1.35$ & $0.60^{*}$ \\
\hline Volatile fine particle number & $5.65 \times 10^{14} * 1.08$ & $4.96 \times 10^{14} * 1.39$ & 0.88 & $3.14 \times 10^{14} * 1.51$ & $0.56^{* *}$ \\
\hline Non-volatile fine particle number & $4.28 \times 10^{14} * 1.26$ & $6.13 \times 10^{14} * 1.23$ & 1.43 & $2.79 \times 10^{14} * 1.27$ & 0.65 \\
\hline Total particle $\left(5<D_{p}<120 \mathrm{~nm}\right)$ volume $\left(\mathrm{mm}^{3}\right)$ & $30.65 * 1.06$ & $37.96 * 1.39$ & 1.24 & $16.37 * 1.54$ & $0.53^{*}$ \\
\hline Volatile particle volume $\left(\mathrm{mm}^{3}\right)$ & $10.30 * 1.30$ & $15.02 * 1.35$ & 1.46 & $6.08 * 2.10$ & 0.59 \\
\hline Non-volatile particle volume $\left(\mathrm{mm}^{3}\right)$ & $20.03 * 1.05$ & $22.75 * 1.44$ & 1.14 & $9.83 * 1.32$ & $0.49^{\star *}$ \\
\hline PSAP black-carbon-equivalent mass at $467 \mathrm{~nm}(\mathrm{mg})$ & $41.29 * 1.18$ & $42.40 * 1.13$ & 1.03 & $17.09 * 1.07$ & $0.41^{\star * *}$ \\
\hline PSAP black-carbon-equivalent mass at $530 \mathrm{~nm}(\mathrm{mg})$ & $39.56 * 1.18$ & $41.07 * 1.13$ & 1.04 & $16.79 * 1.10$ & $0.42^{\star * *}$ \\
\hline PSAP black-carbon-equivalent mass at $660 \mathrm{~nm}(\mathrm{mg})$ & $37.88 * 1.20$ & $41.45 * 1.18$ & 1.09 & $17.51 * 1.16$ & $0.46^{* * *}$ \\
\hline Carbon Monoxide, CO (g) & $6.06 \pm 0.66$ & $4.06 \pm 0.41$ & $0.67^{\star \star \star}$ & $5.12 \pm 1.42$ & 0.85 \\
\hline Nitrogen Oxides, $\mathrm{NO}_{\mathrm{x}}(\mathrm{g})$ & $7.53 \pm 0.21$ & $7.67 \pm 0.58$ & 1.02 & $7.35 \pm 1.44$ & 0.98 \\
\hline Number of Plume Intercepts & 4 & 8 & & 7 & \\
\hline
\end{tabular}

Emissions indices were measured in clear air at a single-engine fuel flow rate of $0.280 \pm 0.020 \mathrm{~kg} \mathrm{~s}^{-1}$. Data are for the left inboard engine (no. 2) at altitudes of 9,140-10,970 m (30,000-36,000 ft). Significance level: $* * * * P<0.001, * * *<<0.01, * * P<0.05, * P<0.1$. Particle emissions indices are reported as the geometric mean $* 1$ g.s.d.; trace-gas emissions indices are reported as the arithmetic mean \pm 1 a.s.d. 
Extended Data Table 6 | Emissions indices for no. 2 engine under low-thrust and cruise conditions

\begin{tabular}{|c|c|c|c|c|c|}
\hline Emissions index (per kg of fuel) & $\begin{array}{c}\text { Medium-sulfur-content } \\
\text { Jet A fuel }\end{array}$ & \multicolumn{2}{|c|}{$\begin{array}{l}\text { Low-sulfur-content } \\
\text { Jet A fuel }\end{array}$} & \multicolumn{2}{|c|}{$\begin{array}{c}\text { 50:50 HEFA:low-sulfur-content } \\
\text { Jet A fuel blend }\end{array}$} \\
\hline Total particle $\left(D_{p}>5 n m\right)$ number & - & - & - & - & - \\
\hline Fine particle $\left(D_{p}>10 \mathrm{~nm}\right)$ number & $8.61 \times 10^{14} * 1.27$ & - & - & $4.39 \times 10^{14} * 1.04$ & $0.51^{\star * *}$ \\
\hline Volatile fine particle number & $5.19 \times 10^{14} * 1.23$ & - & - & $2.48 \times 10^{14} * 1.00$ & $0.48^{* * *}$ \\
\hline Non-volatile fine particle number & $3.39 \times 10^{14} * 1.36$ & - & - & $1.90 \times 10^{14} * 1.09$ & $0.56^{\star \star \star}$ \\
\hline Total particle $\left(5<D_{p}<120 \mathrm{~nm}\right)$ volume $\left(\mathrm{mm}^{3}\right)$ & $20.79 * 1.19$ & - & - & 13.13 & 0.63 \\
\hline PSAP black-carbon-equivalent mass at $467 \mathrm{~nm}(\mathrm{mg})$ & $32.85 * 1.07$ & - & - & 9.53 & 0.29 \\
\hline PSAP black-carbon-equivalent mass at $530 \mathrm{~nm}(\mathrm{mg})$ & $31.90 * 1.04$ & - & - & 7.86 & 0.25 \\
\hline PSAP black-carbon-equivalent mass at $660 \mathrm{~nm}(\mathrm{mg})$ & $32.03 * 1.09$ & - & - & 9.88 & 0.31 \\
\hline Carbon Monoxide, $\mathrm{CO}(\mathrm{g})$ & $8.17 \pm 0.68$ & - & - & $6.33 \pm 0.25$ & $0.77^{* \star *}$ \\
\hline Nitrogen Oxides, $\mathrm{NO}_{\mathrm{x}}(\mathrm{g})$ & $6.82 \pm 0.20$ & - & - & $6.72 \pm 0.12$ & 0.98 \\
\hline Number of Plume Intercepts & 5 & 0 & & 2 & \\
\hline
\end{tabular}




\section{RESEARCH LETTER}

Extended Data Table 7 | Emissions indices for no. 3 engine under low-thrust and cruise conditions

\begin{tabular}{|c|c|c|c|c|c|}
\hline \multirow[b]{2}{*}{ Emissions index (per kg of fuel) } & \multirow{2}{*}{$\begin{array}{c}\text { Medium-sulfur-content } \\
\text { Jet A fuel }\end{array}$} & \multicolumn{2}{|c|}{$\begin{array}{l}\text { Low-sulfur-content } \\
\text { Jet A fuel }\end{array}$} & \multicolumn{2}{|c|}{$\begin{array}{c}\text { 50:50 HEFA:Iow-sulfur-content } \\
\text { Jet A fuel blend }\end{array}$} \\
\hline & & Emissions index & Ratio & Emissions index & Ratio \\
\hline Total particle $\left(D_{p}>5 \mathrm{~nm}\right)$ number & - & - & - & - & - \\
\hline Ultrafine particle $\left(5<D_{p}<10 \mathrm{~nm}\right)$ number & - & - & - & - & - \\
\hline Fine particle $\left(D_{p}>10 \mathrm{~nm}\right)$ number & $4.33 \times 10^{14} * 1.33$ & - & - & $2.26 \times 10^{14} * 1.03$ & $0.52^{\star *}$ \\
\hline Volatile fine particle number & $2.59 \times 10^{14} * 1.27$ & - & - & $1.48 \times 10^{14} * 1.03$ & $0.57^{* *}$ \\
\hline Non-volatile fine particle number & $1.73 \times 10^{14} * 1.43$ & - & - & $7.76 \times 10^{13} * 1.11$ & $0.45^{\star *}$ \\
\hline Total particle $\left(5<D_{p}<120 \mathrm{~nm}\right)$ volume $\left(\mathrm{mm}^{3}\right)$ & $9.46 * 1.14$ & - & - & $4.54 * 1.46$ & $0.48^{*}$ \\
\hline Volatile particle volume $\left(\mathrm{mm}^{3}\right)$ & $6.48 * 1.00$ & - & - & $1.19 * 1.05$ & 0.18 \\
\hline Non-volatile particle volume $\left(\mathrm{mm}^{3}\right)$ & $5.97 * 1.39$ & - & - & $2.33 * 1.25$ & 0.39 \\
\hline PSAP black-carbon-equivalent mass at $467 \mathrm{~nm}(\mathrm{mg})$ & $13.44 * 1.02$ & - & - & $4.21 * 1.08$ & $0.31^{* * * *}$ \\
\hline PSAP black-carbon-equivalent mass at $530 \mathrm{~nm}(\mathrm{mg})$ & $12.73 * 1.03$ & - & - & $4.06 * 1.14$ & $0.32^{\star * * *}$ \\
\hline PSAP black-carbon-equivalent mass at $660 \mathrm{~nm}(\mathrm{mg})$ & $13.07 * 1.09$ & - & - & $4.08 * 1.29$ & $0.31^{* \star *}$ \\
\hline Carbon Monoxide, $\mathrm{CO}(\mathrm{g})$ & $8.14 \pm 0.65$ & - & - & $8.50 \pm 1.72$ & 1.04 \\
\hline Nitrogen Oxides, $\mathrm{NO}_{\mathrm{x}}(\mathrm{g})$ & $6.43 \pm 0.36$ & - & - & $6.19 \pm 0.32$ & 0.96 \\
\hline Number of Plume Intercepts & 4 & 0 & & 4 & \\
\hline
\end{tabular}


Extended Data Table 8 | Fit coefficients for the number size distribution

\begin{tabular}{|c|c|c|c|c|c|c|}
\hline \multirow[b]{2}{*}{ Size Distribution Parameter } & \multicolumn{3}{|c|}{ Medium-sulfur-content Jet A fuel } & \multicolumn{3}{|c|}{ 50:50 HEFA:low-sulfur-content Jet $A$ fuel blend } \\
\hline & $\mathrm{N}\left(\mathrm{kg}^{-1}\right)$ & $\mathrm{D}_{\mathrm{g}, \mathrm{N}}(\mathrm{nm})$ & $\sigma_{\mathbf{g}, \mathbf{N}}$ & $N\left(k^{-1}\right)$ & $D_{g, N}(n m)$ & $\sigma_{\mathbf{g}, \mathbf{N}}$ \\
\hline \multirow{2}{*}{\multicolumn{7}{|c|}{$\begin{array}{l}\text { Total Particle Number, } d\left(E I_{N}\right) / d\left[\log \left(D_{p}\right)\right] \text { : } \\
\text { Engine \#2: }\end{array}$}} \\
\hline & & & & & & \\
\hline High Engine Thrust & $(1.50 \pm 0.03) \times 10^{15}$ & $29.4 \pm 0.4$ & $1.79 \pm 0.02$ & $(1.09 \pm 0.02) \times 10^{15}$ & $26.8 \pm 0.3$ & $1.74 \pm 0.02$ \\
\hline Medium Engine Thrust & $(1.07 \pm 0.02) \times 10^{15}$ & $24.7 \pm 0.4$ & $1.78 \pm 0.03$ & $(6.32 \pm 0.13) \times 10^{14}$ & $24.0 \pm 0.3$ & $1.69 \pm 0.02$ \\
\hline Low Engine Thrust & $(8.28 \pm 0.21) \times 10^{14}$ & $24.8 \pm 0.4$ & $1.72 \pm 0.03$ & $(6.07 \pm 0.67) \times 10^{14}$ & $19.3 \pm 1.8$ & $2.09 \pm 0.21$ \\
\hline \multicolumn{7}{|l|}{ Engine \#3: } \\
\hline High Engine Thrust & $(1.14 \pm 0.02) \times 10^{15}$ & $27.8 \pm 0.3$ & $1.76 \pm 0.02$ & $(8.77 \pm 0.12) \times 10^{14}$ & $25.1 \pm 0.2$ & $1.71 \pm 0.01$ \\
\hline Medium Engine Thrust & $(7.01 \pm 0.17) \times 10^{14}$ & $23.3 \pm 0.3$ & $1.69 \pm 0.02$ & $(3.50 \pm 0.08) \times 10^{14}$ & $21.5 \pm 0.3$ & $1.73 \pm 0.03$ \\
\hline Low Engine Thrust & $(4.68 \pm 0.07) \times 10^{14}$ & $23.0 \pm 0.2$ & $1.66 \pm 0.02$ & $(2.11 \pm 0.25) \times 10^{14}$ & $18.6 \pm 0.9$ & $1.43 \pm 0.08$ \\
\hline \multicolumn{7}{|c|}{$\begin{array}{l}\text { Non-Volatile Particle Number, } d\left(E_{N}\right) / d\left[\log \left(D_{p}\right)\right] \text { : } \\
\text { Engine \#2: }\end{array}$} \\
\hline High Engine Thrust & $(7.64 \pm 0.15) \times 10^{14}$ & $35.3 \pm 0.4$ & $1.72 \pm 0.02$ & $(5.41 \pm 0.15) \times 10^{14}$ & $28.7 \pm 0.5$ & $1.75 \pm 0.03$ \\
\hline Medium Engine Thrust & $(5.00 \pm 0.14) \times 10^{14}$ & $29.7 \pm 0.5$ & $1.64 \pm 0.03$ & $(2.62 \pm 0.07) \times 10^{14}$ & $27.8 \pm 0.4$ & $1.71 \pm 0.02$ \\
\hline Low Engine Thrust & $(4.50 \pm 0.23) \times 10^{14}$ & $25.5 \pm 0.9$ & $1.86 \pm 0.07$ & $(4.15 \pm 0.63) \times 10^{14}$ & $20.9 \pm 2.4$ & $2.03 \pm 0.27$ \\
\hline \multicolumn{7}{|l|}{ Engine \#3: } \\
\hline High Engine Thrust & $(6.30 \pm 0.13) \times 10^{14}$ & $32.5 \pm 0.4$ & $1.71 \pm 0.02$ & $(3.94 \pm 0.12) \times 10^{14}$ & $28.0 \pm 0.5$ & $1.68 \pm 0.03$ \\
\hline Medium Engine Thrust & $(3.18 \pm 0.14) \times 10^{14}$ & $27.0 \pm 0.7$ & $1.63 \pm 0.04$ & $(1.78 \pm 0.06) \times 10^{14}$ & $26.3 \pm 0.5$ & $1.68 \pm 0.03$ \\
\hline Low Engine Thrust & $(2.82 \pm 0.08) \times 10^{14}$ & $23.5 \pm 0.5$ & $1.73 \pm 0.03$ & $(1.09 \pm 0.08) \times 10^{14}$ & $23.4 \pm 0.8$ & $1.58 \pm 0.06$ \\
\hline
\end{tabular}

Log-normal fit coefficients ( \pm 1 a.s.d.) to the geometric mean particle number size distributions measured behind the left and right inboard engines (no. 2 and no. 3 , respectively) at altitudes of $9,140-10,970 \mathrm{~m}(30,000-36,000 \mathrm{ft})$. 


\section{RESEARCH LETTER}

Extended Data Table 9 | Fit coefficients for the volume size distribution

\begin{tabular}{|c|c|c|c|c|c|c|}
\hline \multirow[b]{2}{*}{ Size Distribution Parameter } & \multicolumn{3}{|c|}{ Medium-sulfur-content Jet A fuel } & \multicolumn{3}{|c|}{ 50:50 HEFA:low-sulfur-content Jet A fuel blend } \\
\hline & $V\left(\mathrm{~mm}^{3} \mathrm{~kg}^{-1}\right)$ & $D_{g, v}(n m)$ & $\sigma_{\mathbf{g}, \mathbf{V}}$ & $\mathbf{V}\left(\mathrm{mm}^{3} \mathrm{~kg}^{-1}\right)$ & $D_{g, V}(n m)$ & $\sigma_{\mathbf{g}, \mathbf{V}}$ \\
\hline \multicolumn{7}{|c|}{ Total particle volume, $d\left(E I_{V}\right) / d\left[\log \left(D_{p}\right)\right]$ : } \\
\hline \multicolumn{7}{|c|}{ Engine \#2: } \\
\hline High Engine Thrust & $66.8 \pm 2.4$ & $65.7 \pm 1.2$ & $1.57 \pm 0.03$ & $34.4 \pm 1.1$ & $57.2 \pm 1.0$ & $1.61 \pm 0.03$ \\
\hline Medium Engine Thrust & $28.5 \pm 0.8$ & $57.5 \pm 0.8$ & $1.58 \pm 0.02$ & $14.7 \pm 0.5$ & $52.6 \pm 0.5$ & $1.60 \pm 0.03$ \\
\hline Low Engine Thrust & $19.9 \pm 0.6$ & $51.9 \pm 0.8$ & $1.59 \pm 0.02$ & $13.0 \pm 2.3$ & $61.6 \pm 6.0$ & $1.67 \pm 0.19$ \\
\hline \multicolumn{7}{|l|}{ Engine \#3: } \\
\hline High Engine Thrust & $34.4 \pm 1.0$ & $60.8 \pm 1.0$ & $1.61 \pm 0.03$ & $21.9 \pm 0.6$ & $53.3 \pm 0.7$ & $1.54 \pm 0.02$ \\
\hline Medium Engine Thrust & $14.4 \pm 0.6$ & $50.4 \pm 1.0$ & $1.51 \pm 0.03$ & $6.7 \pm 0.5$ & $51.9 \pm 2.2$ & $1.73 \pm 0.08$ \\
\hline Low Engine Thrust & $8.9 \pm 0.3$ & $48.7 \pm 0.7$ & $1.55 \pm 0.02$ & $3.3 \pm 0.5$ & $49.1 \pm 5.0$ & $1.92 \pm 0.18$ \\
\hline \multirow{2}{*}{\multicolumn{7}{|c|}{$\begin{array}{l}\text { Non-volatile particle volume, } d\left(E I_{V}\right) / d\left[\log \left(D_{p}\right)\right] \text { : } \\
\text { Enqine \#2: }\end{array}$}} \\
\hline & & & & & & \\
\hline High Engine Thrust & $44.1 \pm 1.1$ & $68.3 \pm 0.7$ & $1.46 \pm 0.02$ & $20.4 \pm 0.6$ & $61.2 \pm 0.8$ & $1.54 \pm 0.02$ \\
\hline Medium Engine Thrust & $19.6 \pm 1.1$ & $60.9 \pm 1.8$ & $1.57 \pm 0.05$ & $9.7 \pm 0.5$ & $61.5 \pm 1.6$ & $1.66 \pm 0.05$ \\
\hline Low Engine Thrust & $15.8 \pm 0.8$ & $64.3 \pm 1.8$ & $1.64 \pm 0.05$ & $8.9 \pm 2.9$ & $58 \pm 12$ & $1.77 \pm 0.31$ \\
\hline \multicolumn{7}{|l|}{ Engine \#3: } \\
\hline High Engine Thrust & $37.8 \pm 1.4$ & $73.0 \pm 1.5$ & $1.63 \pm 0.04$ & $14.5 \pm 0.5$ & $60.5 \pm 1.3$ & $1.65 \pm 0.04$ \\
\hline Medium Engine Thrust & $12.6 \pm 1.5$ & $66.7 \pm 5.2$ & $1.80 \pm 0.16$ & $6.0 \pm 0.5$ & $61.8 \pm 3.4$ & $1.85 \pm 0.11$ \\
\hline Low Engine Thrust & $6.1 \pm 0.3$ & $51.8 \pm 1.1$ & $1.56 \pm 0.03$ & $1.9 \pm 0.2$ & $44.9 \pm 1.8$ & $1.57 \pm 0.07$ \\
\hline
\end{tabular}

Log-normal fit coefficients ( \pm 1 a.s.d.) to the geometric mean particle volume size distributions measured behind the left and right inboard engines (no. 2 and no. 3 , respectively) at altitudes of 9,140-10,970 m (30,000-36,000 ft). 